\title{
Risk of Incident Diabetes in Relation to Long-term Exposure to Fine Particulate Matter in Ontario, Canada
}

\author{
Hong Chen, ${ }^{1,2}$ Richard T. Burnett, ${ }^{3}$ Jeffrey C. Kwong, 1,4,5 Paul J. Villeneuve, ${ }^{2,3}$ Mark S. Goldberg, ${ }^{6,7}$ Robert D. Brook, $^{8}$ \\ Aaron van Donkelaar, ${ }^{9}$ Michael Jerrett, ${ }^{10}$ Randall V. Martin, ${ }^{9,11}$ Jeffrey R. Brook, ${ }^{12}$ and Ray Copes ${ }^{1,2}$
}

\begin{abstract}
${ }^{1}$ Public Health Ontario, Toronto, Ontario, Canada; ${ }^{2}$ Dalla Lana School of Public Health, University of Toronto, Toronto, Ontario, Canada; ${ }^{3}$ Population Studies Division, Health Canada, Ottawa, Ontario, Canada; ${ }^{4}$ Institute for Clinical Evaluative Sciences, Toronto, Ontario, Canada; ${ }^{5}$ Department of Family and Community Medicine, University of Toronto, Toronto, Ontario, Canada; ${ }^{6}$ Department of Medicine, McGill University, Montreal, Quebec, Canada; ${ }^{7}$ Division of Clinical Epidemiology, McGill University Health Centre, Montreal, Quebec, Canada; ${ }^{8}$ Division of Cardiovascular Medicine, University of Michigan Medical School, Ann Arbor, Michigan, USA; ${ }^{9}$ Department of Physics and Atmospheric Science, Dalhousie University, Halifax, Nova Scotia, Canada; ${ }^{0}$ Division of Environmental Health Sciences, School of Public Health, University of California, Berkeley, Berkeley, California, USA; ${ }^{11}$ Harvard-Smithsonian Centre for Astrophysics, Cambridge, Massachusetts, USA; ${ }^{12}$ Air Quality Research Division, Environment Canada, Toronto, Ontario, Canada
\end{abstract}

BACKGROUND: Laboratory studies suggest that fine particulate matter $(\leq 2.5 \mu \mathrm{m}$ in diameter; $\mathrm{PM}_{2.5}$ ) can activate pathophysiological responses that may induce insulin resistance and type 2 diabetes. However, epidemiological evidence relating $\mathrm{PM}_{2.5}$ and diabetes is sparse, particularly for incident diabetes.

Овјестіves: We conducted a population-based cohort study to determine whether long-term exposure to ambient $\mathrm{PM}_{2.5}$ is associated with incident diabetes.

METHODS: We assembled a cohort of 62,012 nondiabetic adults who lived in Ontario, Canada, and completed one of five population-based health surveys between 1996 and 2005. Follow-up extended until 31 December 2010. Incident diabetes diagnosed between 1996 and 2010 was ascertained using the Ontario Diabetes Database, a validated registry of persons diagnosed with diabetes (sensitivity $=86 \%$, specificity $=97 \%$ ). Six-year average concentrations of $\mathrm{PM}_{2.5}$ at the postal codes of baseline residences were derived from satellite observations. We used Cox proportional hazards models to estimate the associations, adjusting for various individual-level risk factors and contextual covariates such as smoking, body mass index, physical activity, and neighborhood-level household income. We also conducted multiple sensitivity analyses. In addition, we examined effect modification for selected comorbidities and sociodemographic characteristics.

RESULTS: There were 6,310 incident cases of diabetes over 484,644 total person-years of followup. The adjusted hazard ratio for a $10-\mu \mathrm{g} / \mathrm{m}^{3}$ increase in $\mathrm{PM}_{2.5}$ was 1.11 (95\% CI: $1.02,1.21$ ). Estimated associations were comparable among all sensitivity analyses. We did not find strong evidence of effect modification by comorbidities or sociodemographic covariates.

Conclusions: This study suggests that long-term exposure to $\mathrm{PM}_{2.5}$ may contribute to the development of diabetes.

KEY WORDS: cohort study, diabetes, particulate air pollution.

Environ Health Perspect 121:804-810 (2013). http://dx.doi.org/10.1289/ehp.1205958 [Online 26 April 2013]

Diabetes mellitus and its associated macrovascular (Kannel and McGee 1979; Manson et al. 1991a) and microvascular (Watkins and Edmonds 1983) complications constitute a serious threat to global human health and welfare (Wild et al. 2004). The burden of diabetes relates particularly to type 2 diabetes, which accounts for $90-95 \%$ of cases globally (American Diabetes Association 2012). Although obesity (Colditz et al. 1995), diet (Hu et al. 2001), and physical inactivity (Manson et al. 1991b) have been identified as important risk factors for type 2 diabetes, there is increasing evidence that insulin resistance, the underlying hallmark and pathophysiological mechanism leading to type 2 diabetes, can be aggravated by factors that promote inflammatory responses (Hotamisligil 2006).

It is only recently that ambient air pollution has been implicated in the etiology of type 2 diabetes (Brook et al. 2008). Exposure to air pollution has been associated with cardiovascular-related mortality and morbidity

(Brook et al. 2010; Chen et al. 2008). There pollution (Goldberg et al. 2006; O’Neill et al. 2005). In a mouse model, exposure to fine particulate matter (particles with an aerodynamic diameter $\leq 2.5 \mu \mathrm{m} ; \mathrm{PM}_{2.5}$ ) increased blood glucose and induced adipose inflammation and insulin resistance (Sun et al. 2009). This animal study provides a potential biological basis for the link between air pollution and diabetes.

Because of the ubiquitous nature of expoair pollution on increasing the risk of diabetes may pose a large public health burden. To date, tigated the relationship between air pollution and incident diabetes (Andersen et al. 2012; et al. 2011). Two reported positive associations between incident diabetes and $\mathrm{PM}_{2.5}$ and traffic-related pollutants such as nitrogen oxides et al. 2012; Krämer et al. 2010). However, another study reported no association between incident diabetes and $\mathrm{PM}_{2.5}$ (Puett et al. 2011), and the fourth reported only a small increase in diabetes associated with $\mathrm{NO}_{2}$ (Andersen et al. 2012). Of the four cohort studies, one was based on a general population (Andersen et al. 2012), two included women only (Coogan et al. 2012; Krämer et al. 2010), and one comprised female nurses and male health professionals (Puett et al. 2011).

Given that few epidemiological studies have examined associations between air pollution and diabetes, and because little is known about the association in the general population, we conducted a population-based cohort study of long-term exposure to $\mathrm{PM}_{2.5}$ and incident diabetes in Ontario, Canada.

\section{Materials and Methods}

Study design and population. The study was designed as a follow-up of respondents from Ontario, Canada, to the 1996/1997 cycle of National Population Health Survey of all Canadians (Statistics Canada 2010a) and the 2000/2001, 2002, 2003, and 2005 cycles of the Canadian Community Health Surveys among Canadians $\geq 12$ years of age (Statistics is also evidence that persons with diabetes are particularly susceptible to the acute effects of air sure to air pollution, even a modest effect of only four epidemiological studies have invesCoogan et al. 2012; Krämer et al. 2010; Puett $\left(\mathrm{NO}_{\mathrm{x}}\right)$ and nitrogen dioxide $\left(\mathrm{NO}_{2}\right)($ Coogan
Address correspondence to $\mathrm{H}$. Chen, Public Health Ontario, 480 University Ave., Suite 300, Toronto, Ontario M5G 1V2 Canada. Telephone: (647) 2607109. E-mail: hong.chen@oahpp.ca

Supplemental Material is available online (http:// dx.doi.org/10.1289/ehp.1205958).

This work was supported by the Institute for Clinical Evaluative Sciences, operating funds from Public Health Ontario, and a short-form contract (contract 4500275504) from Health Canada. A.v.D. and R.V.M. were supported by Health Canada and a Collaborative Health Research Projects grant. J.C.K. was supported by a Clinician Scientist Award from the Department of Family and Community Medicine, University of Toronto. The Institute for Clinical Evaluative Sciences is funded by an annual grant from the Ontario Ministry of Health and Long-Term Care.

The opinions, results, and conclusions reported here do not necessarily represent the views of Institute for Clinical Evaluative Sciences or the Ministry of Health and Long-term Care.

The authors declare they have no actual or potential competing financial interests.

Received 1 September 2012; accepted 24 April 2013. 
Canada 2010b). These population-based surveys collected information related to health status, health care utilization, and determinants of health for the Canadian population in all provinces and territories, excluding fulltime members of the Canadian military, institutional residents, and individuals living on Indian Reserves, Crown Lands, and certain remote regions. The same questions were used across surveys. The response rates of the surveys in Ontario varied from 73.4 to $92.8 \%$, depending on the year (Statistics Canada 2010a, 2010b). The surveys have been used in health research, such as estimating the burden of cardiovascular diseases in Canada (Manuel et al. 2003).

The study population for the present analysis comprised all respondents who, at the time of survey, resided in Ontario, were $\geq 35$ years of age, were registered with Ontario's provincial health insurance plan, provided informed consent to share and link their responses to provincial health administrative data, and were free of diabetes. In addition, we restricted our analyses to Canadian-born individuals, because immigrants to Canada have unknown prior exposures and tend to have better health and health behaviors (McDonald and Kennedy 2004), but are more likely to live in areas with higher ground-level concentrations of $\mathrm{PM}_{2.5}$ than those born in Canada (Villeneuve et al. 2011). A total of 62,012 participants were included in the study and they were followed-up from the time of survey until 31 December 2010.

The study was approved by the Research Ethics Board of Sunnybrook Health Sciences Centre in Toronto, Ontario, Canada.

Ascertainment of diabetes and other comorbidities. We used the Ontario Diabetes Database (Toronto, ON, CA), a validated registry of diabetics in Ontario, to identify cohort members with and without diabetes (Hux et al. 2002; Lipscombe and Hux 2007). This database was developed using hospital discharge abstracts from the Canadian Institute for Health Information and physician service claims from the Ontario Health Insurance Plan database (Toronto, ON, CA). The hospital discharge database captures all hospital admissions among Ontario residents, whereas the claims database includes claims from approximately $98 \%$ of Ontario physicians because of the universal nature of the provincial medicare system (Chan 2000; Lipscombe and Hux 2007).

Individuals were entered in the diabetes database if they had at least one hospital admission with a diagnosis of diabetes [International Classification of Diseases, 9th Revision, Clinical Modification (ICD-9CM; Centers for Disease Control and Prevention 2012) diagnostic code 250 or 10th Revision (ICD-10; World Health Organization 1993) code E10-E14 after 2002] or two or more physician claims for diabetes (code 250) within a 2-year period (Hux et al. 2002). Gestational diabetes was excluded. This algorithm has been validated using chart review and shown to have high sensitivity (86\%) and specificity $(97 \%)$ for identifying persons with diabetes (Hux et al. 2002). More recently, a study evaluating medical records of 22 family practitioners and their patients in southwestern Ontario confirmed the high sensitivity and specificity of this algorithm (Harris et al. 2010). Once included in the database, individuals remain in it until death or termination of Ontario health coverage. The eligibility of cohort members for health insurance and their vital status through the followup period were assessed using data from the Registered Persons Database (Toronto, ON, CA), a registry of all Ontario residents who have a health insurance number.

We linked the 62,012 cohort members to the diabetes database using encrypted health insurance numbers. We defined incident diabetes as cases diagnosed between the time of entry into the cohort and the end of followup (31 December 2010). Prevalent cases of diabetes diagnosed before the baseline survey were excluded from the analyses.

In addition, we determined whether participants had any of the following comorbidities at baseline: hypertension, congestive heart failure, acute myocardial infarction, asthma, and chronic obstructive pulmonary disease (COPD). These five comorbidities are often present in diabetic patients (Drury 1983; Fabbri and Rabe 2007; Mannino et al. 2008). We ascertained the five comorbidities using validated registries based on hospital discharge abstracts and physician service claims in Ontario [see Supplemental Material, Comorbidity Ascertainment, pp. 3-4 (http:// dx.doi.org/10.1289/ehp.1205958)] (Gershon et al. 2009a, 2009b; Lee et al. 2003; Tu JV et al. 2001; Tu K et al. 2008).

Assessment of long-term exposure to $P M_{2.5}$. To assess long-term exposure to ambient air pollution, we used satellite-based estimates of surface concentrations of $\mathrm{PM}_{2.5}$ (van Donkelaar et al. 2010). The satellite-based concentrations were derived from aerosol optical depth data from the Moderate Resolution Imaging Spectroradiometer (MODIS) and Multiangle Imaging Spectroradiometer (MISR) instruments onboard the National Aeronautics and Space Administration (NASA)'s Terra satellite (van Donkelaar et al. 2010). Using satellite data collected from 1 January 2001 through 31 December 2006, we derived long-term average concentrations of $\mathrm{PM}_{2.5}$ at a resolution of approximately $10 \times 10 \mathrm{~km}$ and covered all North America below $70^{\circ} \mathrm{N}$, which includes all of Ontario. These satellite-based long-term average concentrations of $\mathrm{PM}_{2.5}$ have been shown to correlate well with ground measurements at fixed-site stations across North America (Pearson correlation coefficient $r=0.77$, $n=1057$ ) (van Donkelaar et al. 2010). These satellite-based estimates have been applied previously to estimate associations between longterm exposure to air pollution and mortality (Crouse et al. 2012; Villeneuve et al. 2011) and to estimate the global burden of illnesses due to air pollution (Brauer et al. 2012). The remote sensing methodology used to estimate ground-level ambient concentrations of $\mathrm{PM}_{2.5}$ have been described in detail elsewhere (van Donkelaar et al. 2010). We assigned exposure by linking the exposure surface concentrations of $\mathrm{PM}_{2.5}$ to subjects' residences at cohort entry using six-character postal codes. Six-character postal codes in urban areas represent the centroid of the blocks in which the cohort members lived.

Potential confounding variables. From the self-reported health surveys, we extracted information on marital status, race/ethnicity (white, black, Asian, Arab, Latin American, other), education attainment (less than high school, high school, some postsecondary, and university), and household income adequacy (lowest income, lower middle income, middle income, upper middle income, and upper income). Household income adequacy is an index used by Statistics Canada that accounts for total household income and household size (Statistics Canada 2010a, 2010b). Because 98\% of the cohort was classified as white, we dichotomized race/ethnicity as white or nonwhite.

In addition, we extracted baseline survey data for height and weight to calculate body mass index (BMI; kilograms per meter squared). We also obtained information on smoking status (never smoker, current smoker, former smoker), alcohol consumption (more than once a month, less than once a month, former drinker, never drank), daily consumption of fruits and vegetables $(<5$ servings/ day, $\geq 5$ servings/day), physical activity ( $\geq 3.0$, $1.5-2.9,<1.5 \mathrm{kcal} / \mathrm{kg} /$ day of energy expenditure for leisure activities), and urban/rural residence. Urban areas are those continuously built-up areas having a population $\geq 1,000$ and a population density $\geq 400 / \mathrm{km}^{2}$ based on current census population counts (Statistics Canada 2010a, 2010b).

Using the Canadian Census data for 1996, 2001, and 2006 (Statistics Canada 2012a, 2012 b, 2012c), we created contextual variables at the census tract level for the proportion of population $\geq 15$ years of age with less than high school education, unemployment rate, and mean household income. Because census tracts are not defined for rural areas, we derived these three variables for rural residents according to their census subdivision, which is the next higher geographic unit, usually 
representing a municipality or equivalent. We assigned the values of contextual variables derived from the 1996/1997 census for individuals who entered the cohort in 1996; from the 2001 census for individuals who entered in $2000 / 2001,2002$, or 2003; and from the 2006 census for individuals who entered in 2005. Census tracts are small and relatively homogeneous geographic units that usually comprise a population of 2,500-8,000.

To control for regional-scale spatial patterns in the incidence of diabetes that could be explained by factors other than pollution, we created a dichotomous indicator variable classifying Ontario into southern and northern regions based on the 14 Ontario Local Health Integrated Networks. The Local Health Integrated Networks are responsible for planning, integrating, and funding various local health care services in Ontario.

Statistical analysis. We used a stratified Cox proportional hazards model with strata defined as single-year age groups, cycle of survey, and region (south/north). We excluded 1,936 individuals with missing data for BMI, and we created for all other covariates a separate category for missing values, leaving 60,076 cohort members in all analyses.

The outcome was the incident diagnosis date of diabetes as indicated in the diabetes database. Follow-up time was measured in days, calculated from the date of interview until the date of incident diabetes, or death, or were no longer eligible for provincial health insurance, or until the end of follow-up (31 December 2010).

We modeled associations between $\mathrm{PM}_{2.5}$ and incident diabetes, adjusting for sex, marital status, education, household income adequacy, race/ethnicity, BMI (a linear term and a quadratic term), physical activity, smoking, drinking, diet, urban residency, hypertension at baseline, area-level unemployment, education, and mean household income at baseline. In separate analyses we also controlled for other comorbidities including congestive heart failure, acute myocardial infarction, COPD, and asthma.

We routinely tested for deviations from the proportional hazards assumption by assessing whether the cross-product of each variable with the natural logarithm of the time variable was statistically significant $(\alpha=0.05)$. We also verified the assumption of linearity for $\mathrm{PM}_{2.5}$ and all other continuous variables by using natural cubic spline functions with two and three degrees of freedom. We examined plots of the concentration-response curves and used the Akaike Information Criterion (AIC) to assess the relative goodness of fit for these models. A difference of $>4$ AIC points is considered to prefer one model over another (Leffondre et al. 2002). Because there was no evidence of departure from linearity for the relation of $\mathrm{PM}_{2.5}$ and diabetes, we report adjusted hazard ratios (HR) and 95\% CIs for every $10-\mu \mathrm{g} / \mathrm{m}^{3}$ increase of $\mathrm{PM}_{2.5}$ (referred to as $\mathrm{HR}_{10}$ ). We chose an increment of $10 \mu \mathrm{g} / \mathrm{m}^{3}$ to facilitate comparisons of our findings with other studies (Coogan et al. 2012; Puett et al. 2011).

In addition, we investigated potential effect modification by age, sex, BMI, education, race/ ethnicity, household income adequacy, physical activity, smoking, and comorbidities by assessing whether the interaction term that was

Table 1. Baseline characteristics of study population $(n=62,012)$.

\begin{tabular}{|c|c|c|c|}
\hline Baseline characteristics & $\begin{array}{c}\text { Mean } \pm \text { SD } \\
\text { or percent }\end{array}$ & Baseline characteristics & $\begin{array}{c}\text { Mean } \pm \text { SD } \\
\text { or percent }\end{array}$ \\
\hline Individual risk factors & & Individual risk factors & \\
\hline Age (years) & $54.9 \pm 14.2$ & Alcohol consumption ${ }^{b}$ & \\
\hline Men & 45 & Regular drinker & 62 \\
\hline Marital status & & Occasional or former drinker & 34 \\
\hline Married & 63 & Never drinker & 4 \\
\hline Single & 11 & Total daily consumption of fruits and vegetables & \\
\hline Separated, widowed, or divorced & 26 & $<5$ times/servings/day & 44 \\
\hline Race & & $\geq 5$ times/servings/day & 29 \\
\hline White & 98 & Missing & 27 \\
\hline Nonwhite & 1 & Energy expenditure $(\mathrm{kcal} / \mathrm{kg} / \mathrm{day})^{c}$ & \\
\hline Missing & 1 & $\geq 3.0$ (active) & 22 \\
\hline BMI $\left(\mathrm{kg} / \mathrm{m}^{2}\right)$ & $26.2 \pm 4.7$ & 1.5-2.9 (moderate) & 25 \\
\hline$<18.5$ & 2 & $<1.5$ (inactive) & 51 \\
\hline $18.5-24.9$ & 41 & Missing & 2 \\
\hline $25.0-29.9$ & 37 & Preexisting comorbidity & \\
\hline$\geq 30$ & 17 & Hypertension & 29 \\
\hline Missing & 3 & Acute myocardial infarction & 2 \\
\hline Education & & Congestive heart failure & 3 \\
\hline$<$ High school & 22 & COPD & 10 \\
\hline High school & 18 & Asthma & 9 \\
\hline Beyond high school & 58 & Proportion of cohort lived in an urban area ${ }^{d}$ & 66 \\
\hline Missing & 2 & Proportion of cohort lived in southern region & 83 \\
\hline Annual household income adequacy ${ }^{a}$ & & Area-level risk factors ${ }^{e}$ & \\
\hline Lowest income quintile & 3 & Percentage $\geq 15$ years of age with less than high school education & 28 \\
\hline Lower-middle income quintile & 7 & Percentage $\geq 15$ years of age without employment & 7 \\
\hline Middle income quintile & 18 & Average household income (Can $\$ 1,000)$ & $62.3 \pm 17.5$ \\
\hline Upper-middle income quintile & 32 & & \\
\hline Upper income quintile & 31 & & \\
\hline Missing & 9 & & \\
\hline \multicolumn{4}{|l|}{ Smoking status } \\
\hline Never smoker & 27 & & \\
\hline Current smoker & 24 & & \\
\hline Former smoker & 41 & & \\
\hline Missing & 8 & & \\
\hline
\end{tabular}

andex used by Statistics Canada (2010a, 2010b) that accounts for total household income and household size. ${ }^{b}$ Regular drinker: $\geq$ once each month; occasional drinker: < once each

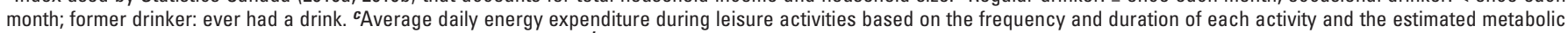

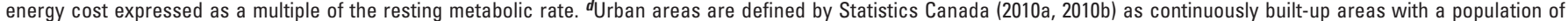

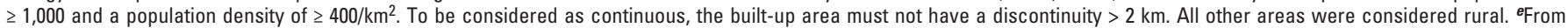
Canadian Census, at the census tract level (Statistics Canada 2012b). 
the cross-product of each variable with $\mathrm{PM}_{2.5}$ value was statistically significant.

Sensitivity analyses. Our main analysis focused on exposure assigned according to residential postal codes at cohort entry. To assess the impact of residential mobility on the effect estimates, we performed three sensitivity analyses by restricting the followup period to first 2 or 5 years, respectively; restricting to 55,708 participants who had lived at their baseline address for at least 5 years before baseline; and modeling timeweighted exposure since cohort entry until the event, with weights for each participant defined by the time spent at each address. For the latter analysis, we obtained residence for each subject and each year from the Registered Persons Database (Toronto, ON, CA) for the period 1996-2010, and derived annual estimates of $\mathrm{PM}_{2.5}$ exposure by assigning the 6-year mean concentration of $\mathrm{PM}_{2.5}$ at each annual postal code.

We also performed additional sensitivity analyses by restricting to participants who had used health services 1-2 years before the baseline because of a concern that the frequency of health care utilization might influence the likelihood of detecting diabetes; excluding participants with missing information on diet because two of the five surveys (1996 and 2002; 27\% of the study population) did not include dietrelated questions; excluding participants from the 2002 cycle of health survey because this survey had the lowest response rate $(73.4 \%)$; and restricting the analysis to southern Ontario, where $83 \%$ of the cohort lived.
We next investigated whether the association might be influenced by spatial dependence among study subjects. We fitted the Cox model with a frailty (random effect) term for Ontario Local Health Integration Networks to allow for the possibility that the effect estimate for diabetes may vary from network to network in the estimation of the main effect and its variance. A gamma distribution for the frailties was assumed, with an exchangeable correlation structure within network. We compared models with and without a frailty term using the AIC. We repeated this analysis by using a frailty term for grids from $\mathrm{PM}_{2.5}$ exposure surface $(10 \times 10 \mathrm{~km})$ as a random effect.

Furthermore, we examined whether associations changed over time by additionally adjusting the Cox model for annual mean concentration of $\mathrm{PM}_{2.5}$ in Ontario (as a linear term) for the period 1996-2010. We derived the long-term trend of $\mathrm{PM}_{2.5}$ using data from all air quality monitoring stations across Ontario that operated for at least half of the study period [see Supplemental Material, Figure S1 (http:// dx.doi.org/10.1289/ehp.1205958)]. We also tested for interactions between time periods (1996-2000 and 2007-2010) and $\mathrm{PM}_{2.5}$.

\section{Results}

The cohort comprised 484,644 person-years of observations. Mean ( \pm SD) follow-up was $8 \pm 3.2$ years. The mean age of the cohort at time of entry was 54.9 years (Table 1 ). Fortyfive percent of the cohort members were men, $63 \%$ were married, $24 \%$ were current smokers, and 54\% were either overweight or obese

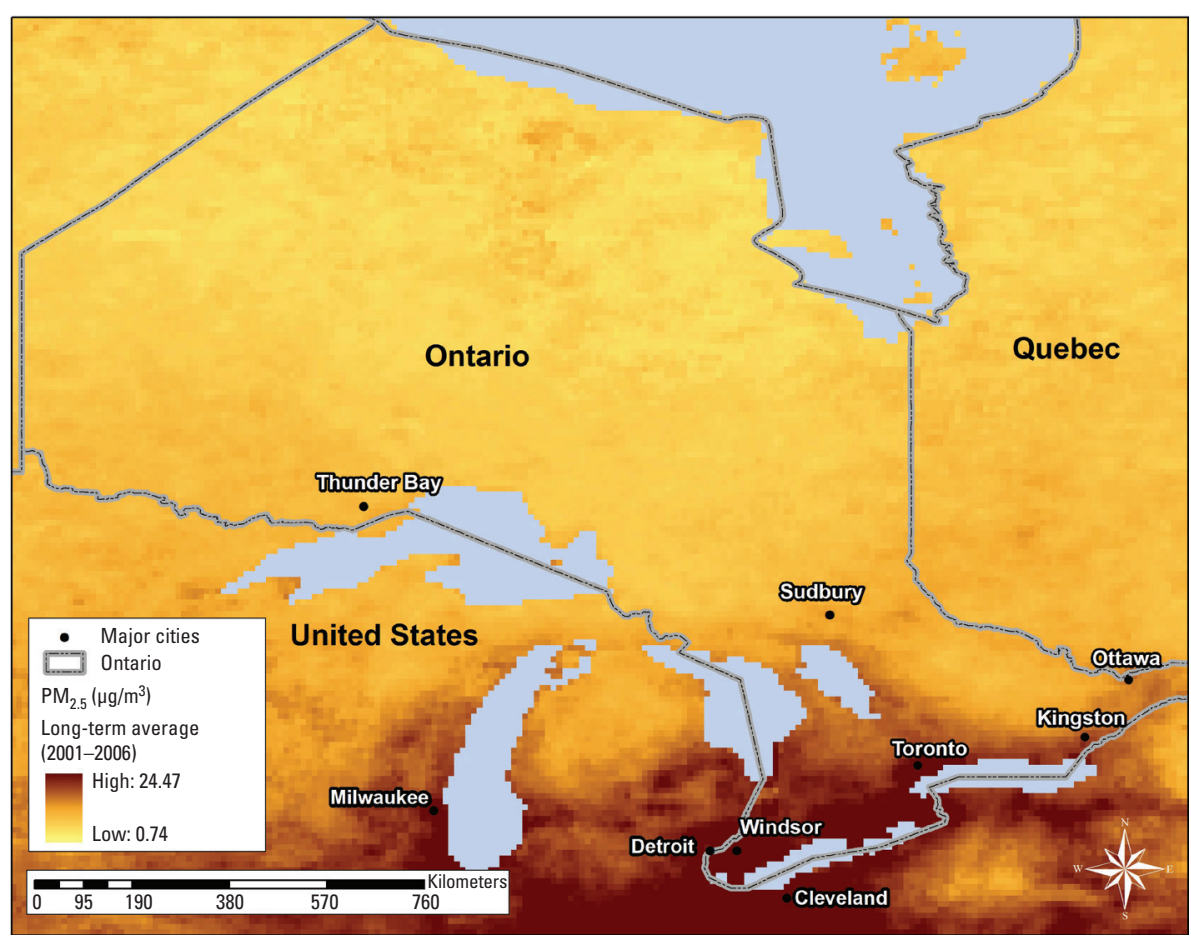

Figure 1. Mean satellite-derived estimates of $\mathrm{PM}_{2.5}$ across Ontario, Canada, 2001-2006.
$\left(\mathrm{BMI} \geq 25 \mathrm{~kg} / \mathrm{m}^{2}\right)$. In addition, $29 \%$ of the cohort had hypertension, $10 \%$ had COPD, and $3 \%$ had congestive heart failure at baseline. Average unemployment among the census tracts was $7 \%$, and mean household income was approximately Can $\$ 62,300$.

Of the cohort, $17 \%, 26 \%, 8 \%, 25 \%$, and $24 \%$ were enrolled from the surveys of 1996/1997, 2000/2001, 2002, 2003, and 2005, respectively. Among cohort members of the five surveys, we identified 1,503, 1,697, $495,1,474$, and 1,141 incident cases of diabetes during the follow-up, with a total of 6,310 cases. Average estimated exposure to $\mathrm{PM}_{2.5}$ during 2001-2006 was $10.6 \mu \mathrm{g} / \mathrm{m}^{3}$ (range, $2.6-19.1 \mu \mathrm{g} / \mathrm{m}^{3}$ ), with the highest average concentrations in southern Ontario (Figure 1).

Associations between diabetes and $P M_{2.5}$. For every $10-\mu \mathrm{g} / \mathrm{m}^{3}$ increase of $\mathrm{PM}_{2.5}$, the hazard ratio for incident diabetes $\left(\mathrm{HR}_{10}\right)$ was 1.08 (95\% CI: $0.99,1.17)$ adjusting for sex and stratifying on age, survey year, and region (Table 2). Adjustment for education, household income, and BMI strengthened the association between $\mathrm{PM}_{2.5}$ and diabetes $\left(\mathrm{HR}_{10} \simeq 1.12\right)$. Additionally controlling for physical activity, smoking, and other individual-level covariates did not appreciably change the HR. In the fully adjusted model that included all individual-level covariates, contextual covariates, and comorbid conditions, the $\mathrm{HR}_{10}$ was 1.11 (95\% CI: $\left.1.02,1.21\right)$. Modeling $\mathrm{PM}_{2.5}$ using natural splines did not improve model fit according to AIC relative to the model that assumed linearity for $\mathrm{PM}_{2.5}$ $(\mathrm{AIC}=57441$ for the model with a linear term of $\mathrm{PM}_{2.5}$; $\mathrm{AIC}=57442$ for the model with natural spline), suggesting a potential log-linear relationship between $\mathrm{PM}_{2.5}$ and incident diabetes [see Supplemental Material, Figure S2 (http://dx.doi.org/10.1289/ehp.1205958)].

We observed larger HRs between diabetes and $\mathrm{PM}_{2.5}$ among 819 participants with preexisting COPD $\left(\mathrm{HR}_{10}=1.33 ; 95 \% \mathrm{CI}\right.$ : $1.03,1.71$ compared with $\mathrm{HR}_{10}=1.08 ; 95 \%$ CI: $0.98,1,18$ for those without COPD; $p$-interaction $=0.13)$, and among women $\left(\mathrm{HR}_{10}=1.17 ; 95 \% \mathrm{CI}: 1.03,1.32\right.$ compared

Table 2. HRs $(95 \% \mathrm{Cls})$ for the association between incident diabetes and a $10-\mu \mathrm{g} / \mathrm{m}^{3}$ increase in $\mathrm{PM}_{2.5}$.

\begin{tabular}{|c|c|}
\hline & $\mathrm{HR}(95 \% \mathrm{CI})$ \\
\hline $\begin{array}{l}\text { Adjusting for sex and stratified by age, } \\
\text { survey year, and region }\end{array}$ & $1.08(0.99,1.17)$ \\
\hline+ All individual-level covariates ${ }^{a}$ & $1.11(1.02,1.21)$ \\
\hline + All neighborhood-level covariates $b$ & $1.11(1.02,1.21)$ \\
\hline+ All other comorbidities ${ }^{c}$ & $1.11(1.02,1.21)$ \\
\hline
\end{tabular}

${ }^{a}$ Adjusted for sex, marital status, education, household income adequacy, BMI, physical activity, smoking, alcohol consumption, diet, race, hypertension, and urban residency. ${ }^{b}$ Also adjusted for neighborhood-level unemployment rate, education, and household income. ${ }^{c}$ Also adjusted for COPD, asthma, congestive heart failure, and acute myocardial infarction. 
with $\mathrm{HR}_{10}=1.03 ; 95 \% \mathrm{CI}: 0.91,1.16$ for men; $p$-interaction $=0.15$ ), and participants $<50$ or $>65$ years of age compared with $50-65$ years $(p$-interaction $=0.19)($ Table 3$)$.
Sensitivity analyses. Restricting the analysis to the first 2 and 5 years of followup slightly increased the effect estimates for diabetes (Table 4). Using time-weighted

Table 3. $\mathrm{HRs}^{a}$ (95\% Cls) for the associations of incident diabetes with a $10-\mu \mathrm{g} / \mathrm{m}^{3}$ increase in $\mathrm{PM}_{2.5}$, by selected characteristics.

\begin{tabular}{|c|c|c|c|}
\hline Characteristic & No. of cases & $\mathrm{HR}(95 \% \mathrm{Cl})$ & $\begin{array}{c}p \text {-Value for interaction } \\
\text { with } \mathrm{PM}_{2.5}{ }^{b}\end{array}$ \\
\hline Age (years) & & & 0.19 \\
\hline$<50$ & 1,690 & $1.19(1.00,1.40)$ & \\
\hline $50-65$ & 2,649 & $1.00(0.88,1.15)$ & \\
\hline$>65$ & 1,971 & $1.18(1.01,1.38)$ & \\
\hline Sex & & & 0.15 \\
\hline Men & 3,239 & $1.03(0.91,1.16)$ & \\
\hline Women & 3,071 & $1.17(1.03,1.32)$ & \\
\hline BMI $\left(\mathrm{kg} / \mathrm{m}^{2}\right)$ & & & 0.63 \\
\hline$<25.0$ & 1,365 & $1.20(1.00,1.45)$ & \\
\hline $25.0-29.9$ & 2,501 & $1.08(0.94,1.25)$ & \\
\hline$\geq 30.0$ & 2,415 & $1.08(0.94,1.25)$ & \\
\hline Education & & & 0.68 \\
\hline$\leq$ High school & 3,085 & $1.13(1.00,1.28)$ & \\
\hline Beyond high school & 3,137 & $1.09(0.96,1.23)$ & \\
\hline Race & & & 0.49 \\
\hline White & 6,145 & $1.11(1.01,1.20)$ & \\
\hline Nonwhite & 127 & $0.79(0.31,2.03)$ & \\
\hline COPD & & & 0.13 \\
\hline Yes & 819 & $1.33(1.03,1.71)$ & \\
\hline No & 5,491 & $1.08(0.98,1.18)$ & \\
\hline Congestive heart failure & & & 0.84 \\
\hline Yes & 231 & $1.16(0.66,2.04)$ & \\
\hline No & 6,097 & $1.09(1.00,1.19)$ & \\
\hline Hypertension & & & 0.51 \\
\hline Yes & 2,882 & $1.08(0.95,1.23)$ & \\
\hline No & 3,428 & $1.14(1.02,1.29)$ & \\
\hline Acute myocardial infarction & & & 0.92 \\
\hline Yes & 209 & $1.05(0.52,2.16)$ & \\
\hline No & 6,101 & $1.11(1.00,1.20)$ & \\
\hline Asthma & & & 0.66 \\
\hline Yes & 666 & $1.04(0.79,1.37)$ & \\
\hline No & 5,644 & $1.11(1.01,1.22)$ & \\
\hline
\end{tabular}

aSeparate models stratified by age, survey year, and region, and adjusted for sex, marital status, education, household income, BMI, physical activity, smoking, alcohol consumption, diet, hypertension, race, urban residency, neighborhoodlevel unemployment rate, neighborhood-level education, and neighborhood-level household income. ${ }^{b}$ Likelihood ratio test.

Table 4. Sensitivity analyses ${ }^{a}$ for the associations of incident diabetes with every $10-\mu \mathrm{g} / \mathrm{m}^{3}$ increase of $\mathrm{PM}_{2.5}$.

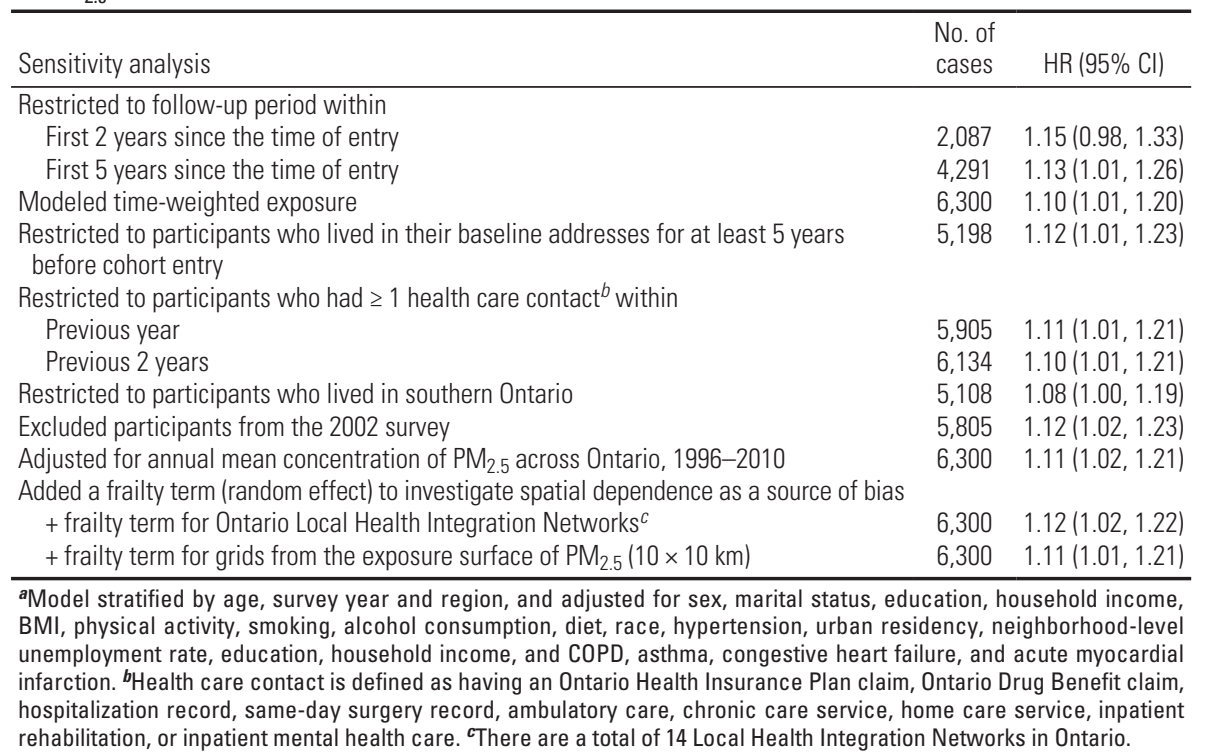

exposure as an alterative exposure metric did not result in appreciable difference in the estimate of association. In addition, the risk estimate was insensitive to exclusion of participants who had recently moved to their baseline addresses before the study, those who had not used health services within the previous 2 years, those who enrolled in the 2002 survey, or those who lived in northern Ontario. Additionally, we excluded participants with missing information on diet, yielding an $\mathrm{HR}_{10}$ of 1.10 (95\% CI: $\left.0.96,1.23\right)$. Furthermore, adding a frailty term to allow for random effects according to Ontario Local Health Integration Networks or grids from $\mathrm{PM}_{2.5}$ exposure surface had little impact on the HR or its variance. Last, there was no strong evidence of variation in the estimated effects of $\mathrm{PM}_{2.5}$ over time, and the test for interactions between periods and $\mathrm{PM}_{2.5}$ was not statistically significant $(p$-interactions $=$ 0.95 and 0.35 ).

\section{Discussion}

In this population-based cohort study of 62,012 adults in Ontario, we found that long-term exposure to $\mathrm{PM}_{2.5}$ was associated with an increased risk of incident diabetes after controlling for various individual and neighborhood covariates. The estimate of association was insensitive to various sensitivity analyses. Additionally, we did not find strong evidence for effect modification by selected comorbidities and sociodemographic covariates.

This study provides evidence for the association between incident diabetes and $\mathrm{PM}_{2.5}$. Few studies have investigated the relationship between incident diabetes and air pollution. In a study of 1,775 women in the Ruhr district of Germany, Krämer et al. (2010) reported an adjusted HR of 1.27 (95\% CI: 1.09, 1.48) for incident diabetes for every interquartile-range (IQR) increase of $\mathrm{PM}_{2.5}\left(\mathrm{IQR}=0.4 / 10^{5} \mathrm{~m}\right.$ using absorbance-based measurement) and $1.42(95 \%$ CI: $1.16,1.73)$ per IQR of $\mathrm{NO}_{2}$ $(\mathrm{IQR}=8 \mathrm{ppb})$. A second study of 4,204 African-American women in Los Angeles, California, reported an HR of 1.25 (95\% CI: $1.07,1.46)$ per IQR of $\mathrm{NO}_{\mathrm{x}}(12.4 \mathrm{ppb})$ and 1.63 (95\% CI: $0.78,3.44$ ) for a $10-\mu \mathrm{g} / \mathrm{m}^{3}$ increase in $\mathrm{PM}_{2.5}$ (Coogan et al. 2012).

In contrast, there was little evidence of an association between incident diabetes and particulate pollutants $\left[\mathrm{PM}_{2.5}, \mathrm{PM}_{2.5-10}\right.$, $\mathrm{PM}_{10}$ (PM with diameter $2.5-10 \mu \mathrm{m}$ and $\leq 10 \mu \mathrm{m})]$ in a cohort of female nurses $(n=74,412)$ or a cohort of male health professionals $(n=15,048)$ living in metropolitan areas of the northeastern and midwestern United States, though residential proximity to roadways was associated with diabetes among the nurses (0-49 m vs. $\geq 200 \mathrm{~m}: \mathrm{HR}=1.14$; 95\% CI: 1.03, 1.27) (Puett et al. 2011). In 
a study of 51,818 participants in Denmark (Andersen et al. 2012), an IQR increase in $\mathrm{NO}_{2}(2.6 \mathrm{ppb})$ was not associated with all cases of diabetes (HR $=1.00 ; 95 \% \mathrm{CI}: 0.97$, $1.04)$, but was associated with cases who were identified using a more strict case definition $(\mathrm{HR}=1.04 ; 95 \% \mathrm{CI}: 1.00,1.08)$. Finally, there was a $4 \%$ increase in the adjusted odds (95\% CI: $0 \%, 8 \%$ ) of diabetes prevalence with each parts per billion increase of $\mathrm{NO}_{2}$ among women in a cross-sectional study of respiratory clinic patients in Hamilton and Toronto, Ontario, but there was no association among men (Brook et al. 2008).

Although associations with diabetes in previous studies were relatively consistent for $\mathrm{NO}_{2}$, associations with $\mathrm{PM}_{2.5}$ were not. The inconsistency may be attributable to chance, differences in population characteristics, misclassification of exposure (resulting from different exposure methods across studies), or inherent differences in the toxicological properties of the pollutants. In these prior studies, positive associations were reported mostly among women (Coogan et al. 2012; Krämer et al. 2010; Puett et al. 2011), and we also found a stronger association among women than men. This stronger association could be attributable to chance, but it may also reflect smaller errors in exposure assessment for women, because women tend to spend more time in and around home than men (Brook et al. 2008). Physiological and lifestyle differences may also contribute to the difference in effect estimates between men and women (Brook et al. 2008). Associations also varied by age, with stronger effects of $\mathrm{PM}_{2.5}$ among those above and below 50-65 years of age at baseline. However, our data are inadequate to investigate this pattern further.

Although increasing BMI is a strong risk factor for diabetes (Colditz et al. 1995), our results do not support the idea that being overweight or obese would enhance susceptibility to the effects of air pollution on diabetes. We did not find strong evidence suggesting that other comorbidities materially altered the association between $\mathrm{PM}_{2.5}$ and diabetes, though power to detect differences was limited. Because inflammation is a key feature of common chronic diseases such as COPD (Rana et al. 2004) and an important pathophysiological response to $\mathrm{PM}_{2.5}$ exposure, further investigation is needed on whether the chronic state of inflammation in patients with these conditions may heighten their susceptibility to diabetes as a consequence of $\mathrm{PM}_{2.5}$ exposure.

To our knowledge, this is the largest study of incident diabetes in a population-based cohort to date. According to the Canadian Census in 2001 (Statistics Canada 2012b), this cohort is representative of the Canadian-born population $\geq 35$ years of age in Ontario (mean age $=53.3$, men $=48 \%$, married $=65 \%$, and white $=99 \%)$. We obtained extensive individual information on known risk factors, and the diagnosis of diabetes was based on a validated registry with very high sensitivity and specificity (Hux et al. 2002). Finally, the use of satellite-based long-term average estimates of $\mathrm{PM}_{2.5}$ ensures virtually complete spatial coverage of $\mathrm{PM}_{2.5}$ among all cohort members. The satellite-based estimates have been shown to correlate well with ground-based measurements (van Donkelaar et al. 2010). The ambient level of $\mathrm{PM}_{2.5}$ in Ontario (annual mean in $2000,11.2 \mu \mathrm{g} / \mathrm{m}^{3}$ ) was much lower than average exposures in previous studies conducted in Los Angeles, California (annual mean $\mathrm{PM}_{2.5}$ in 2000, $20.7 \mu \mathrm{g} / \mathrm{m}^{3}$ ) (Coogan et al. 2012) and in the Ruhr district of Germany (annual mean $\mathrm{PM}_{2.5}$ in 2002, $22.4 \mu \mathrm{g} / \mathrm{m}^{3}$ ) (Krämer et al. 2010).

This study has several limitations that should be considered. First, we could not differentiate between type 1 and type 2 diabetes. However, given that type 2 diabetes accounts for $>90 \%$ of all diabetes cases globally and that all cohort members were $\geq 35$ years of age at entry (mean, - 55 years), the vast majority of incident diabetes in this cohort is expected to be type 2 diabetes (American Diabetes Association 2012).

Second, we could not identify undiagnosed cases of diabetes in the cohort. Although incomplete diagnosis of cohort members is a potential limitation of this study, effect estimates were virtually unchanged when we restricted the analysis to subjects who had used health care services during the 1-2 years before baseline as a proxy indicator of health care utilization, which may be related to the diagnosis of diabetes. Because of universal health care in Ontario, it is expected that we may have underestimated the true effects because this measurement error was likely independent of the exposure.

Third, the spatial pattern in exposure used was derived for the period 2001 to 2006 only. However, the spatial gradients of ambient $\mathrm{PM}_{2.5}$ in Ontario remained stable during the follow-up period (1996-2010) and that variability in the concentrations of $\mathrm{PM}_{2.5}$ is primarily spatial in nature and not temporal [see Supplemental Material, p. 4 (http://dx.doi. org/10.1289/ehp.1205958)]. Studies conducted in diverse locations across the United States have also demonstrated long-term stability in the spatial patterns of $\mathrm{PM}_{2.5}$ (Jerrett et al. 2005; Miller et al. 2007; Pope et al. 2002). We therefore expect that the spatial contrasts in $\mathrm{PM}_{2.5}$ during 2001-2006 is a reasonable representation of longer-term spatial exposure to $\mathrm{PM}_{2.5}$ in Ontario. The spatial resolution of $\mathrm{PM}_{2.5}$ exposure surface (i.e., $10 \times 10 \mathrm{~km}$ ), however, meant that we were unable to estimate associations at finer spatial scale. We also did not have information on daily activity. To assess the impact of residential mobility, we performed various sensitivity analyses, which did not result in appreciable differences in risk estimates. Also, our analyses did not consider the mixture of air pollutants to which subjects may have been exposed.

Fourth, we did not have family history of diabetes or occupational exposure to dust/ fumes in the surveys, and information on potential confounding variables was obtained at baseline only. Twenty-seven percent of the cohort had missing information on diet which was modeled as a separate category. However, there was little change in the association between $\mathrm{PM}_{2.5}$ and diabetes when we excluded members with missing information on diet.

This study suggests that long-term exposure to $\mathrm{PM}_{2.5}$ may contribute to the development of diabetes. A plausible biological mechanism linking exposure to $\mathrm{PM}_{2.5}$ with diabetes may be indirect effects mediated through systemic proinflammatory and oxidative responses (Brook et al. 2008). Sun et al. (2009) found that exposing mice to ambient $\mathrm{PM}_{2.5}$ at the concentration of $72 \mu \mathrm{g} / \mathrm{m}^{3}$ for $6 \mathrm{hr}$ each day over 10 weeks exacerbated insulin resistance by enhancing systemic inflammatory response and inflammation in adipose tissue. Other plausible mechanisms include autonomic nervous system imbalance and endothelial dysfunction that may be triggered by $\mathrm{PM}_{2.5}$, which would in turn induce vasoconstriction and result in reduced insulin sensitivity (Brook et al. 2008; Coogan et al. 2012).

\section{Conclusions}

In summary, we investigated the association between long-term exposure to $\mathrm{PM}_{2.5}$ and the risk of incident diabetes in a large cohort in Ontario, Canada. Results from this study support a possible relationship between $\mathrm{PM}_{2.5}$ and diabetes.

\section{REFERENCES}

American Diabetes Association. 2012. Diagnosis and classification of diabetes mellitus. Diabetes Care 33:S62-S69.

Andersen ZJ, Raaschou-Nielsen 0, Ketzel M, Jensen SS, Hvidberg M, Loft S, et al. 2012. Diabetes incidence and long-term exposure to air pollution. Diabetes Care 35:92-98.

Brauer M, Amann M, Burnett R, Cohen A, Dentener F, Ezzati M, et al. 2012. Exposure assessment for estimation of the global burden of disease attributable to outdoor air pollution. Environ Sci Technol 46:652-660.

Brook RD, Jerrett M, Brook JR, Bard RL, Finkelstein MM. 2008. The relationship between diabetes mellitus and trafficrelated air pollution. J Occup Environ Med 50:32-38.

Brook RD, Rajagopalan S, Pope CA III, Brook JR, Bhatnagar A, Diez-Roux AV, et al. 2010. Particulate matter air pollution and cardiovascular disease: an update to the scientific statement from the American Heart Association. Circulation 121:2331-2378.

Centers for Disease Control and Prevention. 2012. ICD-9-CM Addenda, Conversion Table, and Guidelines. Available: http://www.cdc.gov/nchs/icd/icd9cm_addenda guidelines.htm [accessed 2 June 2013].

Chan B. 1999. Supply of Physicians' Services in Ontario. Toronto:Institute for Clinical Evaluative Sciences. 
Available: http://www.ices.on.ca/file/mod2rp1.pdf [accessed 1 June 2013].

Chen H, Goldberg MS, Villeneuve PJ. 2008. A systematic review of relation between long-term exposure to ambient air pollution and chronic diseases. Rev Environ Health 23:243-296.

Colditz GA, Willett WC, Rotnitzky A, Manson JAE. 1995. Weight gain as a risk factor for clinical diabetes mellitus in women. Ann Intern Med 122:481-486.

Coogan PF, White LF, Jerrett M, Brook RD, Su JG, Seto E, et al. 2012. Air pollution and incidence of hypertension and diabetes mellitus in black women living in Los Angeles: clinical perspective. Circulation 125:767-772.

Crouse DL, Peters PA, van Donkelaar A, Goldberg MS, Villeneuve PJ, Brion 0, et al. 2012. Risk of nonaccidental and cardiovascular mortality in relation to long-term exposure to low concentrations of fine particulate matter: a Canadian national-level cohort study. Environ Health Perspect 120:708-714.

Drury PL. 1983. Diabetes and arterial hypertension. Diabetologia 24:1-9.

Fabbri LM, Rabe KF. 2007. From COPD to chronic systemic inflammatory syndrome? Lancet 370:797-799.

Gershon AS, Wang C, Guan J, Vasilevska-Ristovska J, Cicutto L, To T. 2009a. Identifying individuals with physcian diagnosed COPD in health administrative databases. COPD 6:388-394.

Gershon AS, Wang C, Guan J, Vasilevska-Ristovska J, Cicutto L, To T. 2009b. Identifying patients with physiciandiagnosed asthma in health administrative databases. Can Respir J 16:183-188.

Goldberg MS, Burnett RT, Yale JF, Valois MF, Brook JR. 2006 Associations between ambient air pollution and daily mortality among persons with diabetes and cardiovascular disease. Environ Res 100:255-267.

Harris SB, Richard G, Jordan T, Andrew W, Vijaya C, Moira S, et al. 2010. Investigating concordance in diabetes diagnosis between primary care charts (electronic medical records) and health administrative data: a retrospective cohort study. BMC Health Serv Res 10:347; doi:10.1186/14726963-10-347 [Online 23 December 2010].

Hotamisligil GS. 2006. Inflammation and metabolic disorders. Nature 444:860-867.

Hu FB, Manson JAE, Stampfer MJ, Colditz G, Liu S, Solomon CG, et al. 2001. Diet, lifestyle, and the risk of type 2 diabetes mellitus in women. N Engl J Med 345:790-797.

Hux JE, Ivis F, Flintoft V, Bica A. 2002. Determination of prevalence and incidence using a validated administrative data algorithm. Diabetes Care 25:512-516.

Jerrett M, Burnett RT, Ma R, Pope CA III, Krewski D, Newbold KB et al. 2005. Spatial analysis of air pollution and mortality in Los Angeles. Epidemiology 16:727-736.
Kannel WB, McGee DL. 1979. Diabetes and cardiovascular disease. JAMA 241:2035-2038.

Krämer U, Herder C, Sugiri D, Strassburger K, Schikowski T, Ranft U, et al. 2010. Traffic-related air pollution and incident type 2 diabetes: results from the SALIA Cohort Study. Environ Health Perspect 118:1273-1279.

Lee DS, Austin PC, Rouleau JL, Liu PP, Naimark D, Tu JV. 2003. Predicting mortality among patients hospitalized for heart failure. JAMA 290:2581-2587.

Leffondre K, Abrahamowicz M, Siemiatycki J, Rachet B. 2002. Modeling smoking history: a comparison of different approaches. Am J Epidemiol 156:813-823.

Lipscombe LL, Hux JE. 2007. Trends in diabetes prevalence, incidence, and mortality in Ontario, Canada 1995 to 2005: a population-based study. Lancet 369:750-756.

Mannino DM, Thorn D, Swensen A, Holguin F. 2008. Prevalence and outcomes of diabetes, hypertension and cardiovascuar disease in COPD. Eur Respir J 32:962-969.

Manson JE, Colditz GA, Stampfer MJ, Willett WC Krolewski AS, Rosner B, et al. 1991a. A prospective study f maturity-onset diabetes mellitus and risk of coronary heart disease and stroke in women. Arch Intern Med 151:1141-1147.

Manson JE, Stampfer MJ, Colditz GA, Willett WC, Rosner B, Hennekens $\mathrm{CH}$, et al. 1991b. Physical activity and incidence of non-insulin-dependent diabetes mellitus in women. Lancet 338:774-778.

Manuel DG, Leung M, Nguyen $K$, Tanuseputro $P$, Johansen $H$. 2003. Burden of cardiovascular disease in Canada. Can $J$ Cardiol 19:997-1004.

McDonald JT, Kennedy S. 2004. Insights into the healthy immigrant effect: health status and health service use of immigrants to Canada. Soc Sci Med 59:1613-1627.

Miller KA, Siscovick DS, Sheppard L, Shepherd K, Sullivan JH, Anderson GL, et al. 2007. Long-term exposure to air pollution and incidence of cardiovascular events in women. N Engl J Med 356:447-458.

O'Neill MS, Veves A, Zanobetti A, Sarnat JA, Gold DR, Economides PA, et al. 2005. Diabetes enhances vulner ability to particulate air pollution-associated impairment in vascular reactivity and endothelial function. Circulation 111:2913-2920.

Pope CA III, Burnett RT, Thun MJ, Calle EE, Krewski D, Ito K, et al. 2002. Lung cancer, cardiopulmonary mortality, and long-term exposure to fine particulate air pollution. JAMA 287:1132-1141.

Puett RC, Hart JE, Schwartz J, Hu FB, Liese AD, Laden F. 2011. Are particulate matter exposures associated with risk of type 2 diabetes? Environ Health Perspect 119:384-389.

Rana JS, Mittleman MA, Sheikh J, Hu FB, Manson JAE, Colditz GA, et al. 2004. Chronic obstructive pulmonary disease, asthma, and risk of type 2 diabetes in women. Diabetes Care 27:2478-2484.

Statistics Canada. 2010a. National Population Health Survey Household Component - Longitudinal (NPHS). Available: http://www23.statcan.gc.ca:81/imdb/p2SV.pl?Function=9 etSurvey\&SDDS $=3225 \&$ lang $=e n \& d b=i m d b \& a d m=8 \& d i s=2$ [accessed 6 May 2012]

Statistics Canada. 2010b. Canadian Community Health Survey - Annual Component (CCHS). Available: http:// www.statcan.gc.ca/cgi-bin/imdb/p2SV.pl?Function=get Survey \&SDDS=3226\&lang $=e n \& d b=i m d b \& a d m=8 \& d i s=2$ [accessed 6 May 2012]

Statistics Canada. 2012a. 1996 Census of Canada. Available: http://www12.statcan.gc.ca/english/census01/info/ census96.cfm [accessed 1 June 2012]

Statistics Canada. 2012b. 2001 Census of Canada. Available: http://www12.statcan.ca/english/census01/home/Index. cfm [accessed 1 June 2012]

Statistics Canada. 2012c. 2006 Census of Canada. Available: http://www12.statcan.gc.ca/census-recensement/2006/ index-eng.cfm [accessed 1 June 2012].

Sun 0 , Yue $P$, Deiuliis JA, Lumeng CN, Kampfrath $T$, Mikolaj MB, et al. 2009. Ambient air pollution exaggerates adipose inflammation and insulin resistance in a mouse model of diet-induced obesity. Circulation 119:538-546.

Tu JV, Austin PC, Walld R, Roos L, Agras J, McDonald KM. 2001. Development and validation of the Ontario acute myocardial infarction mortality prediction rules. J Am Coll Cardiol 37:992-997.

Tu K, Chen Z, Lipscombe LL. 2008. Prevalence and incidence of hypertension from 1995 to 2005: a population-based study. CMAJ 178:1429-1435

van Donkelaar A, Martin RV, Brauer M, Kahn R, Levy R Verduzco C, et al. 2010. Global estimates of ambient fine particulate matter concentrations from satellite-based aerosol optical depth: development and application. Environ Health Perspect 118:847-855.

Villeneuve PJ, Goldberg MS, Burnett RT, van Donkelaar A Chen H, Martin RV. 2011. Associations between cigarette smoking, obesity, sociodemographic characteristics and remote-sensing-derived estimates of ambient $\mathrm{PM}_{2.5}$ results from a Canadian population-based survey. 0ccup Environ Med 68:920-927.

Watkins PJ, Edmonds ME. 1983. Sympathetic nerve failure in diabetes. Diabetologia 25:73-77.

Wild SH, Roglic G, Green A, Sicree R, King H. 2004. Global prevalence of diabetes: estimates for the year 2000 and projections for 2030. Diabetes Care 27:1047-1053.

World Health Organization. 1993. International Classification of Diseases, 10th Revision. Geneva:World Health Organization. 